\title{
SEZOLAMIDE: ADDITIVITY TO TIMOLOL TWICE DAILY
}

\author{
FRANS GUNNING', ALAIN BÉCHETOILLE ${ }^{2}$, ERIK A. LIPPA ${ }^{3}$, NORBERT PFEIFFER ${ }^{4}$. \\ JURGEN GERLING ${ }^{4}$, DANIEL HOLDER ${ }^{3}$, COLEEN CLINESCHMIDT ${ }^{3}$, AGNES BUNTINX $^{3}$, \\ FRANÇOISE L. BRUNNER-FERBER ${ }^{3}$, FRANZ GREHN ${ }^{4}$, ERIK GREVE' \\ Amsterdam, The Netherlands, Angers, France: West Point. Philadelphia. USA: and Freihurg. Germany.
}

\begin{abstract}
SUMMARY
Sezolamide, a potent topical carbonic anhydrase inhibitor previously known as MK-417, was studied to determine its ocular hypotensive activity in patients with elevated intraocular pressure while on continuing therapy with topical timolol. This was a three-centre, doublemasked, randomised, placebo-controlled, parallel study in 36 patients with bilateral primary open angle glaucoma or ocular hypertension on therapy receiving $0.5 \%$ timolol twice daily, with a morning intraocular pressure greater than or equal to $22 \mathrm{mmHg}$ in both eyes $2-4$ hours following an 8 a.m. dose of timolol. Sezolamide $1.8 \%$ or placebo twice daily was added to treatment with timolol on the evening of day 1 and continued for 2 weeks. Twelve-hour diurnal curves were performed before the study on day 1 (timolol alone) and on day 15. Intraocular pressure measurements were also taken on days 2 and 8 at 8 a.m. and 9 a.m. Patients who received timolol and sezolamide showed additional intraocular pressure reductions from day 1 (timolol alone) of 8.0 to $15.5 \%$, which were significant at all times. At hours 1, 2, 4 and 8 the reductions in intraocular pressure observed in the group receiving sezolamide and timolol were significantly greater than those in the group receiving timolol and placebo.
\end{abstract}

Over the past 5 years, significant progress has been made in developing a potent topically active carbonic anhydrase inhibitor. The racemate MK-927 was the first topical carbonic anhydrase inhibitor to demonstrate substantial prolonged clinically significant activity in patients with bilateral primary open angle glaucoma and ocular hypertension. ${ }^{1-5}$

'Glaucoma Centre. Academic Medical Centre. Amsterdam. The Netherlands.

'Department of Ophthalmology, University of Angers. Angers. France.

'Departments of Clinical Research. (E.A.L. and C.C.). Clinical Pharmacology (F.L.B.-F. and A. B.) and Biostatistics (D.H.), Merck Sharp \& Dohme Research Laboratories. West Point. Philadelphia. USA

${ }^{4}$ Department of Ophthalmology; University Hospital. Frciburg. Germany.

Correspondence to: Frans P. Gunning. MD. Glaucoma Centre. Academic Medical Centre. Meibergdreef 9. 1105 AZ Amsterdam. The Netherlands.
Sezolamide, previously known as MK-417, is the more potent of the two stereoisomers of MK-927 in inhibiting human carbonic anhydrase isoenzyme II, the isoenzyme found in ciliary processes. Sezolamide, the S-enantiomer of MK-927, has demonstrated activity in vitro approximately 8) times that of the R-enantiomer of MK-927 (concentrations of $0.54 \mathrm{nmol} / \mathrm{l}$ and $44 \mathrm{nmol} / \mathrm{l}$, respectively. inhibiting activity of human carbonic anhydrase isoenzyme Il by $50 \%$ ). ${ }^{\circ}$ Clinically, sezolamide has also demonstrated greater activity than MK-927 both after single-dose and after twice daily administration in patients. In a three-period, single-dose crossover study in patients, a peak mean percentage decrease in intraocular pressure from predose levels of $24 \%$ was demonstrated after $1 \%$ sezolamide versus a $20 \%$ decrease after $1 \%$ MK-927.? A maximum intraocular pressure lowering activity from time-matched baseline diurnal curve values of about $20 \%$ was observed after multiple-dose twice daily administration of $1.8 \%$ sezolamide in patients with primary open angle glaucoma or ocular hypertension. ${ }^{x}$ However. the overall duration of action was insufficient for twice daily administration.

This study was undertaken to explore the potential efficacy of sezolamide as adjunctive therapy. In particular, we investigated the degree of additional intraocular pressurelowering achieved by sezolamide in patients with elevated intraocular pressure while on treatment with topical timolol maleate. A twice daily dosing regimen was selected in order to study whether the three times daily frequency necessary when used as monotherapy" could be reduced with concomitant use of a beta-blocker. To our knowledge, this is the first study to investigate the additive hypotensive effect of timolol maleate and an active topical carbonic anhydrase inhibitor in patients with glaucoma.

\section{PATIENTS AND METHODS}

\section{Materials}

All patients received $0.5 \%$ timolol maleate ophthalmic solution. In addition patients were allocated to receive $1.8 \%$ sezolamide hydrochloride ophthalmic solution or vehicle (placebo). The ophthalmic formulation of sezola- 
mide utilised in this study was isotonic, buffered at pH 5.2, preserved with benzalkonium chloride, and included $0.5 \%$ hydroxyethyl cellulose as a viscosity enhancer.

\section{Patient Selection and Entry}

This study was approved by the Ethical Review Board at each participating hospital and each patient gave informed consent before entering the study. Patients were recruited if they had a diagnosis of bilateral primary open angle glaucoma or ocular hypertension and were between 45 and 85 years of age. Females were required to be either postmenopausal or sterilised. Ocular hypotensive therapy was to include an ophthalmic beta-blocker for at least 5 weeks prior to entry into the study and to consist solely of $0.5 \%$ timolol twice daily at 8 a.m. and 8 p.m. during the last 3 weeks of this period. This last 3 weeks provided a run-in period on timolol. In order to proceed into the 2-week adjunctive therapy study patients were required to have an intraocular pressure greater than or equal to $22 \mathrm{mmHg}$ in both eyes simultaneously between 2 and 4 hours following the 8 a.m. dose of timolol administered by the investigator on the last day of the run-in period.

Exclusion criteria included inability to discontinue concomitant systemic or dermatological medication known to affect intraocular pressure, any concurrent ocular therapy other than the study drug, a history of intraocular surgery, best corrected Snellen visual acuity at distance equal to or worse than 20/100 in both eyes, recent signs of ocular infection or inflammation, and any contraindication to therapy with a beta-blocker. Furthermore, patients with a history of poor ocular response to previous therapy with an oral or topical carbonic anhydrase inhibitor or an ophthalmic beta-blocker were excluded from this study.

\section{Study Design}

This was a three-centre, double-masked, randomised, placebo-controlled, parallel study. All patients received $0.5 \%$ timolol maleate at 8 a.m. and 8 p.m. followed by $1.8 \%$ sezolamide hydrochloride or placebo (vehicle) administered to each eye at 8:10 p.m. and 8:10 a.m. The first dose was given at $8: 10$ p.m. on day 1 . Treatment with timolol and the study drug continued for 14 days. The final dose of both was given on the morning of day 15 .

A prestudy 12-hour diurnal intraocular pressure curve was performed on day 1 . This provided a baseline diurnal curve after 3 weeks on timolol. Intraocular pressure measurements were taken immediately prior to the timolol dose at 8 a.m. and then every 2 hours until 8 p.m. The patient was then observed for 30 minutes following the first dose of study drug at 8:10 p.m., returning on days 2 and 8 for intraocular pressure measurements at 8 a.m. (before the timolol dose) and 9 a.m. ( 1 hour after the dose). On day 15 , intraocular pressure was again measured immediately prior to the timolol dose at $8 \mathrm{a} . \mathrm{m}$. and then every 2 hours until 8 p.m.

Within each centre, all measurements of intraocular pressure for a given patient were performed by the same person using the same Goldmann applanation tonometer.
A fluorescein-benoxinate solution was instilled to permit the examination.

Patients were closely monitored throughout the study with evaluations of symptoms, visual acuity, and external and anterior segment signs. Both prestudy and poststudy examinations included dilated ophthalmoscopy and visual field examination.

\section{Statistical Methods}

The primary variables of interest were change and percentage change in intraocular pressure from prestudy values at the same timepoint. Within-treatment group changes from prestudy values were tested using the matched-pair $t$-test. Tests for significant differences between treatment groups were based on analysis of variance, the model including terms for treatment, investigator, prior therapy and a prior therapy by treatment interaction. All tests were two-sided with type I error set at $\alpha=0.05$.

Results were analysed with respect to both 'worse eye' and 'average eye' (mean of right and left eye). For this purpose, the worse eye was defined as follows:

1. The eye with the greater intraocular pressure at 8 a.m. on day 1.

2. If intraocular pressure was equal in both eyes at 8 a.m. on day 1 , immediately predose, then the worse eye was that with the greater intraocular pressure at $8 \mathrm{a} . \mathrm{m}$. on the day when the intraocular pressure entry criteria were fulfilled.

3. If intraocular pressure was equal in both eyes at 8 a.m. on both day 1 and the day when the intraocular pressure entry criteria were fulfilled, then the worse eye was defined as the right eye.

Since results for the worse eye and the average eye analyses were very similar, only the results for the worse eye analysis are given below. The analysis was based on the 36 patients who completed the study per protocol.

\section{RESULTS}

Thirty-nine patients entered the study. One patient dropped out of the study for reasons unrelated to test drug administered. Two patients were excluded from analysis because they received oral beta-blockers during the study period. Thirty-six patients completed the study per protocol (11-13 patients per centre). There were 12 men and 24 women with a mean age of 63.5 years (range 46-79 years). Prior to the timolol run-in period 21 patients had been on therapy with only a beta-blocker, 10 had previously received a beta-blocker plus one or more additional agents, and 5 patients had either been on no prior therapy or on non-beta-blocker therapy. The distribution by iris colour was: blue, 18; green, 3 ; hazel or light golden brown, 4 ; brown, 8 ; and dark brown, 3 (these being the five categories into which iris colour had been separated). There were no significant differences between treatment groups with respect to the above parameters. There were 20 patients in the sezolamide treatment group and 16 patients in the placebo group. 


\section{Intraocular Pressure}

Table I presents the mean intraocular pressure data and standard deviations for each treatment group. Although intraocular pressures on day 1 were generally slightly greater for the sezolamide treatment group, these differences were not significant. Fig. 1 depicts graphically the data for $1.8 \%$ sezolamide and placebo with respect to mean percentage change in intraocular pressure from day 1. In the table and figure, hour 0 represents 8 a.m., immediately prior to dosing with timolol; hour 1 is 9 a.m., 1 hour after the timolol dose and 50 minutes after the study drug instillation; etc. On day 2 , the percentage decrease in intraocular pressure from day 1 (timolol alone) was significant at both 8 and 9 a.m. for sezolamide and placebo administered concurrently with timolol. At 1 hour after the dose, the decrease demonstrated by sezolamide $(15.9 \%)$ was significantly greater than that for placebo $(6.9 \%, p=0.03)$. On day 8,1 hour after the dose, the decrease demonstrated by sezolamide $(13.2 \%)$ was also significantly different from that for placebo $(5.0 \%$, $p=0.04)$.

On day 15 , the sezolamide group demonstrated a percentage decrease in intraocular pressure from day 1 ranging from $8.0 \%$ to $15.5 \%$, which was significant at all times $(p<0.05$ at 8 a.m.; $p<0.01$ at 9 a.m. to 8 p.m. $)$ and significantly different from the decrease exhibited by the placebo-treated group (3.7-9.0\%) at 1, 2, 4, 8 and 10 hours after the dose $(p<0.01$ at hours 1, 2 and 10;p = 0.04 at hour 4 , and $p=0.05$ at hour 8 ). There was some indication that patients not previously receiving a beta-blocker prior to the run-in period may have responded better to sezolamide than patients receiving a beta-blocker.

\section{Symptoms}

Seven of 20 patients receiving sezolamide reported generally mild, transient local irritation (burning, stinging, etc.) compared with only 1 of 16 patients receiving placebo. Seven patients receiving placebo complained of transient, generally mild blurred vision as compared with 1 patient receiving sezolamide. Both sezolamide and pla-

Table I. Mean intraocular pressures (worse eye, $\mathrm{mmHg}$ )

\begin{tabular}{lcccc}
\hline Time & Day 1 & Day 2 & Day 8 & Day 1.5 \\
\hline Sezolamide treatment group $(n=20)$ & & \\
8:(0) a.m. & 25.9 & 23.0 & 23.9 & 23.3 \\
9:00 a.m. & 25.9 & 21.6 & 22.0 & 22.0 \\
10:00 a.m. & 25.8 & & & 21.9 \\
Noon & 26.2 & & 22.2 \\
2:00 p.m. & 22.5 & & 19.2 \\
4:(00 p.m. & 23.4 & & 20.4 \\
6:00 p.m. & 23.7 & & 20.9 \\
8:(0) p.m. & 23.1 & & 21.2 \\
Placeho treatment group $(n=16)$ & & \\
8:00 a.m. & 24.0 & 21.7 & 23.4 & 22.5 \\
9:00 a.m. & 23.7 & 21.6 & 22.8 & 22.4 \\
10:(0) a.m. & 23.8 & & 22.4 \\
Noon & 24.0 & & 22.4 \\
2:()0 p.m. & 22.4 & & 20.1 \\
4:00 p.m. & 22.8 & & 20.8 \\
6:00 p.m. & 22.8 & & 21.7 \\
8:00 p.m. & 22.3 & & 20.3 \\
\hline
\end{tabular}

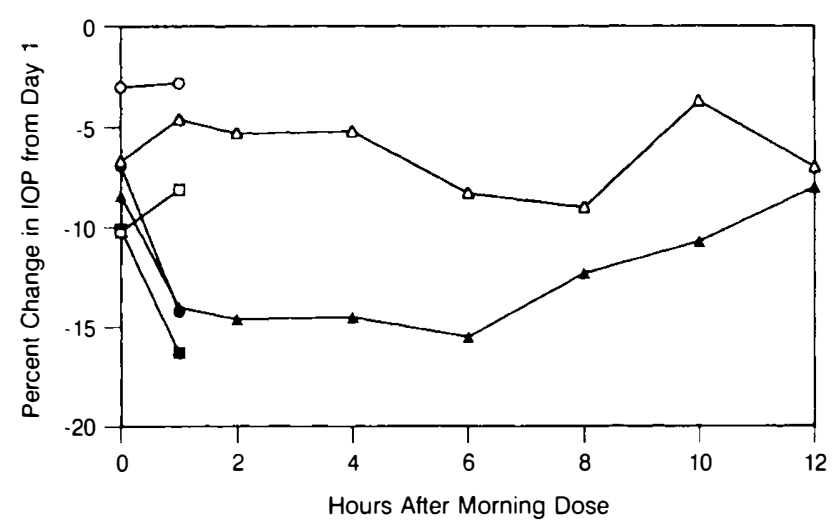

Fig. 1. Percentage change in intraocular pressure from day 1 (w'orse eve). Sezolamide plus timolol: day 2, filled squares; day 8, filled circles; day 15. filled triangles. Placeho plus timolol: day 2, open squares; day 8, open circles; day 15, open triangles.

cebo were considered reasonably well tolerated by patients.

\section{Evaluation of Ophthalmoscopy and Visual Field Behaviour}

There were no clinically significant changes with respect to the data of ophthalmoscopic appearance and visual field examination.

\section{COMMENT}

Oral carbonic anhydrase inhibitors such as acetazolamide have been available for over three decades ${ }^{10}$ and topical non-selective beta-blockers such as timolol for the last 13 years. "Combination treatment with these agents is often necessary in case of uncontrolled glaucoma. The first authors to study the additive hypotensive effect of oral acetazolamide with timolol were Boger, ${ }^{12}$ Nielsen $^{13}$ and Bischoff $^{14}$ in 1978. These studies showed that glaucoma patients not controlled by timolol $0.25 \%$ or $0.5 \%$ alone, could benefit from additional therapy with acetazolamide. Other topical or systemic beta-blockers also demonstrated an additive intraocular pressure-lowering effect when used in combination with systemic carbonic anhydrase inhibitors. ${ }^{15-17}$ An additive intraocular pressure-lowering effect has also been shown when timolol $0.25 \%$ was given to patients already receiving oral acetazolamide. ${ }^{18}$

Both carbonic anhydrase inhibitors and beta-blockers appear to reduce intraocular pressure by decreasing aqueous humour formation. ${ }^{10,19-24}$ Most authors postulate that the two drug classes affect aqueous humour dynamics by different pathways. ${ }^{19.25}$ Investigators have hypothesised that timolol maleate and other beta-adrenergic blockers decrease aqueous humour production by antagonising the effect of circulating catecholamines on the beta-2-adrenergic receptors in the ciliary body. ${ }^{26}$ The effect of carbonic anhydrase inhibitors may be mediated by inhibition of carbonic anhydrase isoenzyme II located in the ciliary processes. Bicarbonate synthesis and flow into the posterior chamber is reduced and this appears to be linked to decreased sodium and fluid movement, resulting in a decreased rate of aqueous humour formation. ${ }^{27.28}$ 
The intraocular pressure-lowering effect of systemic carbonic anhydrase inhibitors when administered concurrently to patients receiving topical beta-blocking agents has been extensively investigated. ${ }^{15-17,19,23-25,29}$ Partial additivity of effect (measured in terms of intraocular pressure and outflow pressure) in excess of $50 \%$ has been demonstrated. ${ }^{23,24}$ Combined intraocular pressure-lowering activity in these experiments ranged from $32 \%$ to $40 \%$ from baseline intraocular pressure (without medication). The mean additional intraocular pressure-lowering effect of oral acetazolamide given to patients already treated with timolol was between 2.7 and $4.4 \mathrm{mmHg}(13.4-22 \%)$ after 1 week of combined therapy. The outflow pressure (defined as intraocular pressure minus episcleral venous pressure) was reduced by $62-64 \%$ from baseline level (without medication) when combining timolol with oral acetazolamide, $500 \mathrm{mg}$ twice daily. Similar results are reported for the relatively beta-1-selective topical betablocker, betaxolol. ${ }^{17}$

Patient compliance with oral carbonic anhydrase inhibitors is poor, predominantly because of well-known side effects such as paraesthesias, the general malaise symptom complex, gastrointestinal symptoms and renal calculi. A topical carbonic anhydrase inhibitor with limited systemic side effects and substantial additivity to beta-blockers would be a welcome addition to the medical treatment of glaucoma and may lend itself to formulation in a topical CAI/beta-blocker combination product. Recent results indicate that no metabolic effects were observed after 2 weeks of therapy with $1.8 \%$ sezolamide given four times daily in a carefully controlled study of potential biochemical effects. ${ }^{30}$

To our knowledge, this is the first study to demonstrate the additional intraocular pressure-lowering effect of a topical carbonic anhydrase inhibitor in patients receiving a topical beta-blocker. The additive effect of timolol with sezolamide was greater than that with placebo. However, optimal efficacy may require a more potent compound.

There was some degree of intraocular pressure-lowering in the placebo treatment group. Patient compliance for timolol may have improved during the course of the study, a well-known phenomenon in clinical trials. In addition, some of the decrease may represent regression to the mean following fulfilment of the intraocular pressure entry criteria. It is unlikely that placebo (i.e. vehicle) could have enhanced ocular penetration of timolol as placebo was administered 10 minutes after the timolol dose.

Side effects such as burning and stinging are rarely reported for timolol maleate. In this study the local symptoms attributable to sezolamide were generally mild and transient, with no severe or serious adverse reactions.

We conclude that there is an additional statistically significant intraocular pressure-lowering effect, of approximately $2 \mathrm{mmHg}$, when $1.8 \%$ sezolamide twice daily is administered adjunctively to patients whose pressures on timolol are in the low twenties. The side effects were transient, local and minimal. This study indicates that a combination of a topical carbonic anhydrase inhibitor and a beta-blocker may have potential in the treatment of glaucoma. Further clinical trials with sezolamide and other topical carbonic anhydrase inhibitors are indicated to further define their role as adjunctive agents.

Dr. Lippa is a director, Clinical Research; Mr. Holder is a statistician, Biostatistics; Ms. A. Buntinx and Dr. Brunner-Ferber are Associate Directors, Clinical Pharmacology; Ms. Clineschmidt is a Senior Medical Program Coordinator, Clinical Research; and all are employed at Merck \& Co., Inc. Drs. Gunning, Béchetoille, Pfeiffer, Gerling, Grehn and Greve have no commercial or proprietary interest in the drug sezolamide.

Key words: Carbonic anhydrase inhibitors, Glaucoma, Sezolamide, Timolol.

\section{REFERENCES}

1. Bron AM, Lippa EA, Hofmann HM, Feicht B, Royer J, Brunner-Ferber F, et al.: MK-927: a topically effective carbonic anhydrase inhibitor in patients. Arch Ophthalmol 1989, 107: 1143-6.

2. Pfeiffer N, Hennekes R, Lippa EA, Grehn F, Garus H, Brunner-Ferber FL: Single-dose efficacy of a novel topical carbonic anhydrase inhibitor. Br J Ophthalmol 1990, 74: 405.

3. Higginbotham EJ, Kass MA, Lippa EA, Batenhorst RL, Panebianco DL, Wilensky JT: MK-927, a topical carbonic anhydrase inhibitor; dose response and duration of action. Arch Ophthalmol 1990, 108: 65.

4. Serle JB, Lustgarten JS, Lippa EA, Camras CB, Panebianco DL, Podos SM: MK-927, a topical carbonic anhydrase inhibitor: dose response and reproducibility. Arch Ophthalmol 1990, 108: 838.

5. Lippa EA, Aasved H, Airaksinen PJ, Alm A, Bertelsen T, Calissendorff $\mathrm{B}$, et al.: Multiple-dose dose-response relationship for the topical carbonic anhydrase inhibitor MK-927. Arch Ophthalmol 1991, 109: 46.

6. Baldwin J, Ponticello G, Anderson P, Christy M, Murcko M, Randall W, et al:: Thienothiopyran-2-sulfonamides: novel topically active carbonic anhydrase inhibitors for the treatment of glaucoma. J Med Chem 1989, 32: 2510.

7. Diestelhorst M, Béchetoille A, Lippa EA, Brunner-Ferber FL, Krieglstein GK: Zur Stereospezifität der Augendrucksenkung eines lokal applizierten Karboanhydrasehemmers. Fortschr Ophthalmol 1990, 87: 131.

8. Bron A, Lippa EA, Gunning F, Bénichou MD, Lesure P, Sirbat $\mathrm{D}$, et al:: Multiple-dose efficacy comparison of the two topical carbonic anhydrase inhibitors MK-417 and MK-927. Arch Ophthalmol 1991, 109: 50.

9. Lippa EA, Sherwood M, Laibovitz RM, Miller E, McMahon C, Clineschmidt C, Caprioli J: MK-417 vs. timolol : comparative activity. Invest Ophthalmol Vis Sci 1990, 31 (suppl): 232.

10. Becker B: Decrease in intraocular pressure by a carbonic anhydrase inhibitor, Diamox. Am J Ophthamol 1954,37: 13.

11. Katz IM, Hubbard WA, Getson AJ, Gould AL: Intraocular pressure decrease in normal volunteers following timolol ophthalmic solution. Invest Ophthalmol Vis Sci 1976, 15: 498.

12. Boger WP, III, Puliafito CA, Steinert RF, Langston DP: Long-term experience with timolol ophthalmic solution in patients with open angle glaucoma. Ophthalmology 1978, 85: 259.

13. Nielsen NV: Timolol. Hypotensive effect, used alone and in combination for treatment of increased intraocular pressure. Acta Ophthalmol 1978, 56: 504-9.

14. Bischoff P: Erfahrungen mit timolol in der glaukom therapie. Klin Monatsbl Augenheilkd 1978, 173: 202.

15. Leydhecker W, Krieglstein GK: The intraocular pressure responses of low-dose bupranolol (Ophtorenin) and meth- 
azolamide (Neptazane) in glaucomatous eyes. A controlled clinical study. Albrecht Von Graefes Arch Klin Exp Ophthalmol 1979, 210: 135.

16. MacDonald MJ, Gore SM, Cullen PM, Phillips CI: Comparison of ocular hypotensive effects of acetazolamide and atenolol. Br J Ophthalmol 1977, 61: 345.

17. Smith JP, Weeks RH, Newland EF, Ward RL: Betaxolol and acetazolamide. Combined ocular hypotensive effect. Arch Ophthalmol 1984, 102: 1794.

18. Keates EU: Evaluation of timolol maleate combination therapy in chronic open-angle glaucoma. Am J Ophthalmol 1979, 88: 565.

19. Dailey RA, Brubaker RF, Bourne WM: The effects of timolol maleate and acetazolamide on the rate of aqueous formation in normal human subjects. Am J Ophthalmol 1982, 93: 232.

20. Coakes RL, Brubaker RF: The mechanism of timolol in lowering intraocular pressure in the normal eye. Arch Ophthalmol 1978, 96: 2045.

21. Yablonski ME, Zimmerman TJ, Waltman SR, Becker B: A fluorophotometric study of the effect of topical timolol on aqueous humour dynamics. Exp Eye Res 1978, 27: 135.

22. Zimmerman TJ, Harbin R, Pett M, Kaufman HE: Timolol and facility of outflow. Invest Ophthalmol Vis Sci 1977, 16: 623.

23. Berson FG, Epstein DL: Separate and combined effect of timolol maleate and acetazolamide in open-angle glaucoma. Am J Ophthalmol 1981, 92: 788.
24. Kass MA, Korey M, Gordon M, Becker B: Timolol and acetazolamide. A study of concurrent administration. Arch Ophthalmol 1982, 100: 941.

25. Scharrer A, Ober M: Timolol and acetazolamide in the treatment of increased intraocular pressure (author's translation). Albrecht Von Graefes Arch Klin Exp Ophthalmol 1979, 212: 129.

26. Hoskins HD, Kass MA, editors. Adrenergic antagonists. In: Becker-Shaffers's diagnosis and therapy of the glaucomas, 6th ed. St. Louis, Mosby, 1989, p. 454.

27. Maren TH: The rates of movement of $\mathrm{NA}^{+}, \mathrm{Cl}^{-}$, and $\mathrm{HCO}_{3}^{-}$ from plasma to posterior chamber: effect of acetazolamide and relation to the treatment of glaucoma. Invest Ophthalmol 1976, 15: 356.

28. Maren TH: Carbonic anhydrase: general perspectives and advances in glaucoma research. Drug Dev Res 1987, 10: 255.

29. Calissendorff B, Maren N, Wettrell K, Ostberg A: Timolol versus pilocarpine separately or combined with acetazolamide effects on intraocular pressure. Acta Ophthalmol 1980 , 58: 624 .

30. Buclin T., Biollaz J, Lippa E A, Brunner-Ferber F, Van Melle $\mathrm{G}$, Munafo A, et al.: Absence of metabolic effects of the topical carbonic anhydrase inhibitors MK-927 and sezolamide during prolonged ocular administration to normal subjects. $J$ Clin Pharmacol Ther In press. 